\title{
What are Canadian emergency physicians' attitudes and self-perceived competence toward patients who present with suicidal ideation?
}

\author{
Justin Fernandes ${ }^{1} \cdot$ Frank X. Scheuermeyer $^{2} \cdot$ Apu T. Chakraborty $^{3} \cdot$ William G. Honer $^{3} \cdot$ David Barbic $^{2}$ (I)
}

Received: 25 February 2021 / Accepted: 1 June 2021 / Published online: 1 July 2021

() The Author(s), under exclusive licence to Canadian Association of Emergency Physicians (CAEP)/ Association Canadienne de Médecine d'Urgence (ACMU) 2021

\begin{abstract}
Introduction Suicide is the 9th leading cause of death in Canada, and a common reason for patients to present to Canadian emergency departments (ED). Little knowledge exists around Canadian emergency physicians (EPs) attitudes toward and understanding of individuals with suicidal ideation.

Methods We developed a web-based survey on suicide knowledge, which was pilot tested by two EPs and one psychiatrist for clarity and content. The survey was distributed via email to attending physician members of the Canadian Association of Emergency Physicians. Data were described using counts, means, medians and interquartile ranges. The Understanding of Suicidal Patients (USP) Scale is an 11-point questionnaire to assess healthcare providers' attitudes toward individuals with suicidal ideation. Other questions pertaining to suicidal ideation, self-perceptions on ability to treat suicidal patients, and personal experiences with suicide were asked in Likert format.

Results One hundred eighty-eight Canadian EPs responded to the survey (15\% response rate), with a median age of 49 (IQR 39-55), academic practice reported by $55 \%$ of respondents, and $65 \%$ of respondents identified as male. The mean USP score was 21.8 (95\% CI 21.1-22.5), which indicates a generally positive attitude and willingness to provide care for suicidal patients. Only $17 \%$ of respondents had participated in specific training for treatment of suicidal patients in the last five years, while the majority of respondents estimate treating 5-15 patients with suicidal ideation a month. Sixty four percent of respondents indicated they had the skills to screen patients for suicidal ideation, but less than one-third felt they could create a personalized safety plan for patients.

Conclusions Respondents have a generally positive attitude toward treating individuals with suicidal ideation. Respondents scored highly on the USP scale that measured willingness to provide care for and empathize with suicidal patients. Respondents felt they had the skills to adequately screen patients for suicidal ideation. Key gaps in knowledge were identified suggesting improved residency and ongoing medical education opportunities are needed to better improve care for this vulnerable population.
\end{abstract}

Keywords Emergency medicine $\cdot$ Attitude $\cdot$ Physician $\cdot$ Suicide

\section{Résumé}

Introduction Le suicide est la $9^{\mathrm{e}}$ principale cause de décès au Canada et une raison courante pour laquelle les patients se présentent aux services d'urgence (SU) canadiens. Il existe peu de connaissances sur les attitudes et la compréhension des médecins d'urgence canadiens à l'égard des personnes ayant des idées suicidaires.

David Barbic

david.barbic@gmail.com

1 Faculty of Medicine, University of British Columbia, Vancouver, BC, Canada

2 Department of Emergency Medicine, University of British Columbia, Vancouver, BC, Canada

3 Department of Psychiatry, University of British Columbia, Vancouver, BC, Canada 
Méthodes Nous avons développé une enquête en ligne sur la connaissance du suicide, qui a été testée par deux médecins d'urgence et un psychiatre pour en vérifier la clarté et le contenu. Le sondage a été distribué par courriel aux médecins traitants membres de l'Association canadienne des médecins d'urgence. Les données ont été décrites à l'aide de chiffres, de moyennes, de médianes et d'intervalles interquartiles. L'échelle de compréhension des patients suicidaires (USP) est un questionnaire en 11 points visant à évaluer l'attitude des prestataires de soins de santé envers les personnes ayant des idées suicidaires. D'autres questions portant sur les idées suicidaires, les perceptions de soi sur la capacité de traiter les patients suicidaires et les expériences personnelles de suicide ont été posées en format Likert.

Résultats Cent quatre-vingt-huit médecins d'urgence canadiens ont répondu à l'enquête (taux de réponse de $15 \%$ ), avec un âge médian de 49 ans (IQR 39-55), une pratique universitaire déclarée par $55 \%$ des répondants, et $65 \%$ des répondants se sont identifiés comme des hommes. Le score USP moyen était de 21,8 (IC à $95 \%$ 21,1-22,5), ce qui indique une attitude généralement positive et une volonté de fournir des soins aux patients suicidaires. Seuls $17 \%$ des répondants ont participé à une formation spécifique pour le traitement des patients suicidaires au cours des cinq dernières années, tandis que la majorité des répondants estiment traiter 5 à 15 patients ayant des idées suicidaires par mois. Soixante-quatre pour cent des répondants ont indiqué qu'ils possédaient les compétences nécessaires pour dépister les idées suicidaires chez les patients, mais moins d'un tiers estimaient qu'ils pouvaient créer un plan de sécurité personnalisé pour les patients.

Conclusions Les répondants ont une attitude généralement positive à l'égard du traitement des personnes ayant des idées suicidaires. Les répondants ont obtenu un score élevé sur l'échelle USP qui mesurait la volonté de fournir des soins et de l'empathie envers les patients suicidaires. Les répondants estimaient avoir les compétences nécessaires pour dépister adéquatement les idées suicidaires chez les patients. Des lacunes importantes dans les connaissances ont été identifiées, ce qui suggère que de meilleures possibilités de formation en résidence et de formation médicale continue sont nécessaires pour améliorer les soins offerts à cette population vulnérable.

\section{Clinician's capsule}

\section{What is known about the topic?}

No evidence exists on the attitudes of Canadian emergency physicians toward patients presenting to the emergency department with suicidal ideation.

\section{What did this study ask?}

This study used the Understanding of Suicidal Patients Scale to assess physicians' attitudes toward individuals who present with suicidal ideation.

\section{What did this study find?}

Respondents have a positive attitude toward treating persons with suicidal ideation, yet identified important gaps in skills and training.

Why dose this study matter to clinicians?

Key gaps in knowledge were identified suggesting improved residency and ongoing medical education opportunities are needed to better improve care.

\section{Introduction}

The global conversation around mental health and mental illness has grown in recent years, yet the stigma associated with mental health concerns and suicide can negatively impact patient experiences and quality of care [1]. Despite good intentions, hidden and unknown biases may influence the actions of healthcare providers and impact the care provided to patients presenting with suicidal ideation [2].
Unbiased, compassionate care is especially important in the context of the emergency department (ED), since evidence exists that suicidal ideation is present in approximately $10 \%$ of adults who present to the ED, even if their chief complaint may be unrelated [3]. Recent Canadian data indicates that approximately $1.5 \%$ of all ED visits per year are for suicidal ideation [4], and in many EDs, the initial assessment and management of these patients are managed by emergency physicians (EPs).

Previous work has demonstrated that some medical specialists find it challenging to be empathetic toward individuals with suicidal ideation [2]. It has been shown that some EPs may lack the skills and confidence in suicide risk stratification, counseling of patients and the generation of individualized safety plans [5]. Unfortunately, limited data exist on the attitudes of EPs in the care of patients with suicidal ideation. As a result, a key step in improving the care of patients presenting to the ED with suicidal ideation, is understanding EP attitudes toward this group of patients.

The specific objectives of this study were to (1) measure the attitudes of EPs toward patients presenting to the ED with suicidal ideation, and (2) measure the self-reported skills and training of EPs to care for this patient population.

\section{Methods}

This study was approved by the University of British Columbia Providence Health Care Research Ethics Board (\#H19-01836). 


\section{Study design and population}

We developed an anonymous online survey, which was pilot tested for content and clarity by two EPs and one psychiatrist. This was distributed via email to 1,217 attending EPs who were members of the Canadian Association of Emergency Physicians (CAEP) and had consented to receive surveys. A reminder email was sent at two and four weeks to the distribution list. The full survey consisted of four components and is included in full as an appendix (ESM Appendix 1).

Survey questions were developed from a review of literature or taken directly from other studies [6] to provide better comparability. We included demographic questions to allow description of study respondents. To measure the understanding of and willingness to provide care for patients presenting with suicidal ideation, we used the Understanding Suicidal Patients (USP) scale, an 11-item questionnaire scored in a 5-point Likert format with individual scores summed to provide a composite score from 11 to 55, where lower scores indicate more understanding and empathy [7]. This tool has been validated on nurses [7], emergency department personnel [8], physicians [2], and other healthcare providers [9]. In this study, we use the 5-point version, which is used in more recent studies utilizing this scale [2, $8,9]$.

\section{Outcomes}

The primary outcome of this study was the proportion of emergency physicians reporting a USP score less than 23, signifying high empathy [2, 8, 9]. Secondary outcomes included self-reported physician skills and training for managing patients with suicidal ideation.

\section{Analyses}

Statistical analyses were performed using Excel (Microsoft Corp, Redmond, WA) and Stata 16 (StataCorp, College Station, TX). Counts, means, medians, $95 \%$ confidence intervals and interquartile ranges were used to describe the data. Cronbach's alpha was calculated for USP scale to validate inter-item reliability for the survey. We employed a Bayesian ordered logistic regression analysis, controlling for age, gender, years in practice, province of practice, recent prior training, and hospital type to determine if there were any significant predictors of USP scores (Fig. 1).

\section{Results}

One hundred eighty-eight Canadian EPs responded to the survey ( $15 \%$ response rate), with a median age of 49 (IQR $39-55)$, academic practice reported by $55 \%$ of respondents, and $65 \%$ of respondents identified as male. The majority of respondents (54\%) treat an estimated 5-15 patients with suicidal ideation each month, over half (51\%) had some personal familiarity with suicide (Table 1).

One hundred sixty-eight Canadian EPs completed the USP scale. The proportion of EPs reporting a total USP score less than 23 was $52 \%$. The mean USP score was 21.8 (SD 4.7; median 22) (Table 1). The item with the greatest contribution to a high empathy score was the statement, "I would like to help a person that has attempted suicide" (mean: 1.5, SD 0.6, see ESM Appendix).

Bayesian ordinal logistic regression controlling for age, gender, years in practice, province of practice, recent prior training, and hospital type revealed no significant predictors of better EP empathy scores.
Fig. 1 Distribution of respondent USP scale scores

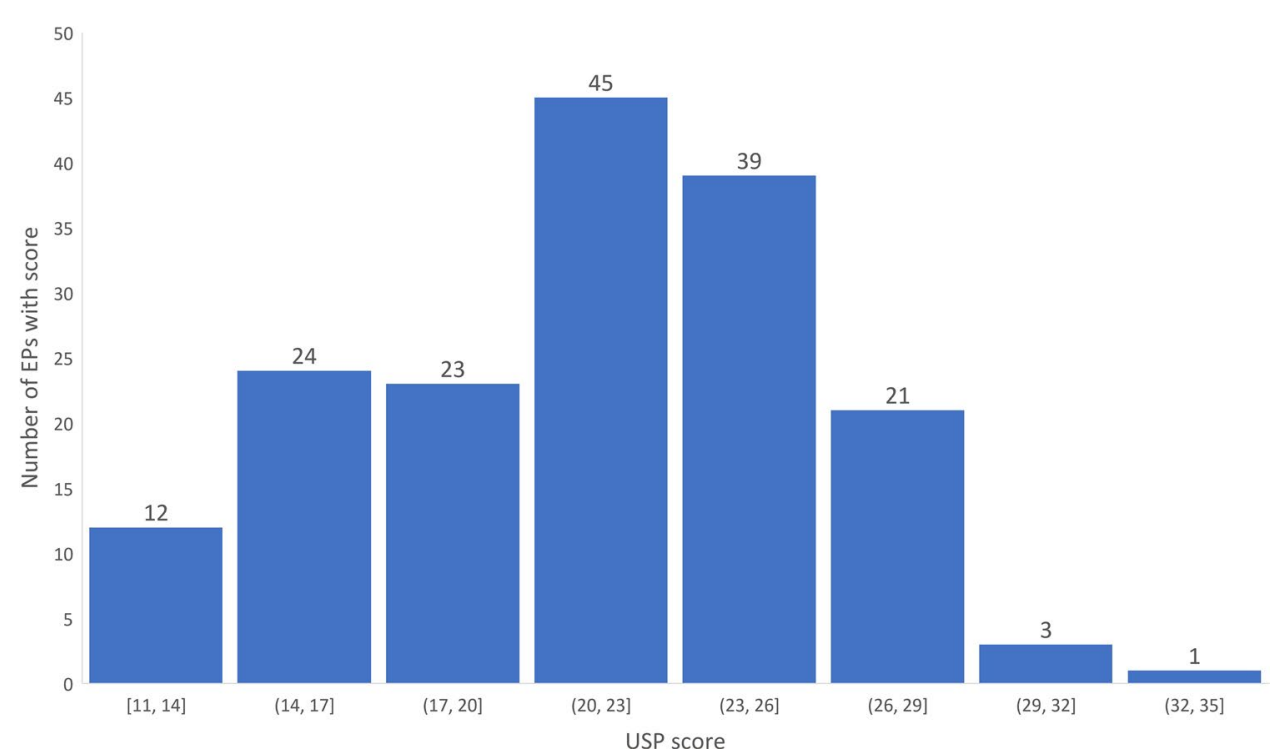


Table 1 Characteristics of survey respondents $(N=188)$

\begin{tabular}{|c|c|}
\hline \multicolumn{2}{|l|}{ Age } \\
\hline$<35(\%)$ & $18(10 \%)$ \\
\hline $35-54(\%)$ & $116(62 \%)$ \\
\hline $55+(\%)$ & $54(29 \%)$ \\
\hline Median (IQR) & $49(39-55)$ \\
\hline \multicolumn{2}{|l|}{ Years of practice } \\
\hline Median (IQR) & $18(7-25)$ \\
\hline \multicolumn{2}{|l|}{ Sex } \\
\hline Male (\%) & $122(65 \%)$ \\
\hline Female $(\%)$ & $66(35 \%)$ \\
\hline \multicolumn{2}{|l|}{ Type of practice } \\
\hline Academic $(\%)$ & $104(55 \%)$ \\
\hline Community (urban/suburban)(\%) & $53(28 \%)$ \\
\hline Rural $(\%)$ & $31(16 \%)$ \\
\hline \multicolumn{2}{|l|}{ Number of patients with suicidal ideation treated per month } \\
\hline $0-5(\%)$ & $41(22 \%)$ \\
\hline $5-15(\%)$ & $102(54 \%)$ \\
\hline $15-25(\%)$ & $24(13 \%)$ \\
\hline $25+(\%)$ & $6(3 \%)$ \\
\hline Did not answer question (\%) & $15(8 \%)$ \\
\hline \multicolumn{2}{|l|}{ Familiarity with suicide or suicidal ideation outside the professional sphere } \\
\hline Personal experience with close friend, colleague, or family member & $75(40 \%)$ \\
\hline Personally considered or attempted suicide & $4(2 \%)$ \\
\hline Both an experience with someone else and personally considered suicide & $16(9 \%)$ \\
\hline Total & $95(51 \%)$ \\
\hline No experience with suicide outside the professional sphere & $93(49 \%)$ \\
\hline \multicolumn{2}{|l|}{ Summary of USP empathy scores (see ESM Appendix for more details) } \\
\hline Mean USP score (SD) & $21.8(4.7)$ \\
\hline Median USP score & 22 \\
\hline Proportion of sample with total USP score below 23 & $52 \%$ \\
\hline
\end{tabular}

In this study, Cronbach's alpha for the USP-scale was 0.75 .

Suicide risk assessment and treatment training (education of any length within the last 5 years, including during residency) was reported by $17 \%$ of respondents, and two thirds (64\%) reported having the skills needed to screen patients for suicidality (ESM Appendix 1). Less than one-third of EPs $(30 \%)$ felt confident in their ability to create a personalized safety plan for patients, although a majority $(60 \%)$ were confident in their ability to find referral resources. Half of EPs (48\%) felt that most suicides are preventable, and many believed that suicidal ideation was associated with psychiatric complaints (73\%) and trauma, abuse, or social isolation (83\%) (ESM Appendix 1).

\section{Discussion}

In this cross-sectional study of Canadian emergency physicians (EPs), our respondents demonstrate empathy toward suicidal patients although there are gaps in their perceived individual self-competency in managing this population.

Our findings indicate that respondents generally have positive attitudes toward patients presenting with suicidal ideation. Our respondents' mean USP scores compare favorably with findings from other studies of general practitioners (19.4) [2], psychiatrists (18.4) [2], internists (22.7) [2] and various healthcare providers working in emergency departments (28.6) [8] and mental health clinics $(21.8,18.7)$ [9], including physicians, nurses, and psychologists, indicating a high degree of empathy from Canadian EPs. Our study failed to identify any significant predictors of higher physician 
empathy; however, our study may have been underpowered to detect these differences should they exist.

\section{Clinical and research implications}

Our study highlights that respondents feel there is potential for improvement in managing patients with suicidal ideation. Only $64 \%$ of respondents believed they could screen patients, and as management becomes more complex, from assessing severity, to counseling, and finally creating a safety plan, respondents progressively felt less confident in their skills. These findings are similar to recent work from the United States demonstrating a mismatch between perceived skills for screening, management and counseling [5]. Our findings may stem from minimal recent training, as only $17 \%$ of respondents had received relevant training in the last five years. The current curricula of emergency medicine postgraduate training programs and Continuing Medical Education in Canada display a concerning scarcity in training opportunities to provide EPs with the necessary skills to care for this high-risk patient population. With the exception of screening patients, for which our respondents self-scored lower, these responses are similar to prior work [6] and illustrate a need for enhanced training and ongoing medical education in this area. Future research may focus on the utility of universal screening for suicidal ideation and the efficacy of educational interventions for physicians.

The chief study limitation is the $15 \%$ response rate. However, our demographic data has good sampling from rural and community practices and roughly aligns with recent data from the Canadian Medical Association on emergency physician gender and age distributions which states that $69 \%$ of EPs are male and $13 \%$ are under age 35,57\% are between age 35 and 54, and $30 \%$ are age 55 and over (see Appendix), which may help to mitigate this bias. Physicians who feel a personal connection to this topic may be more likely to respond, and almost half of our respondents had experienced the effects of suicide in their personal lives; physicians who find the topic uncomfortable may have avoided responding, however recent Canadian data suggests that our sample closely aligns with existing experiences of Canadian EPs [10]. As this is a topic that is already understudied in Canada, the low response rate may underscore the importance of our study in advancing this conversation. "Suicidal ideation" encompasses a broad spectrum of risk, and it is likely that EPs may be more comfortable managing some patients with suicidal ideation than others.

\section{Conclusion}

In this cross-sectional survey of Canadian EPs, respondents had a generally positive attitude toward treating individuals who with suicidal ideation. Respondents felt they had the skills to adequately screen patients for suicidal ideation. Key gaps in knowledge were identified suggesting improved residency and ongoing medical education opportunities are needed to better improve care for this vulnerable population.

Supplementary Information The online version contains supplementary material available at https://doi.org/10.1007/s43678-021-00157-0.

\section{Declarations}

Conflict of interest The authors declare that they have no conflict of interest.

\section{References}

1. Henderson C, Noblett J, Parke H, et al. Mental health-related stigma in health care and health-care settings. Lancet Psychiatry. 2014;1(6):467-82.

2. Grimholt TK, Haavet OR, Jacobsen D, Sandvik L, Ekeberg O. Perceived competence and attitudes towards patients with suicidal behaviour: a survey of general practitioners, psychiatrists and internists. BMC Health Serv Res. 2014;14:208.

3. Ilgen MA, Walton MA, Cunningham RM, et al. Recent suicidal ideation among patients in an inner city emergency department. Suic Life Threat Behav. 2009;39:508-17.

4. Barbic D, et al. The impact of COVID-19 on mental health and substance use visits to emergency departments in the Vancouver Coastal health region. CJEM. 2021 (in press).

5. Betz ME, Sullivan AF, Manton AP, et al. Knowledge, attitudes, and practices of emergency department providers in the care of suicidal patients. Depress Anxiety. 2013;30:1005-12.

6. Betz ME, Arias SA, Miller M, et al. Change in emergency department providers' beliefs and practices after use of new protocols for suicidal patients. Psychiatr Serv (Washington, DC). 2015;66:625-31.

7. Samuelsson M, Asberg M, Gustavsson JP. Attitudes of psychiatric nursing personnel towards patients who have attempted suicide. Acta Psychiatr Scand. 1997;95:222-30.

8. Suominen K, Suokas J, Lönnqvist J. Attitudes of general hospital emergency room personnel towards attempted suicide patients. Nord J Psychiatry. 2007;61:387-92.

9. Norheim AB, Grimholt TK, Loskutova E, Ekeberg O. Attitudes toward suicidal behaviour among professionals at mental health outpatient clinics in Stavropol, Russia and Oslo, Norway. BMC Psychiatry. 2016;16:268.

10. Lim R, Aarsen KV, Gray S, Rang L, Fitzpatrick J, Fischer L. Emergency medicine physician burnout and wellness in Canada before COVID19: a national survey. CJEM. 2020;22:603-7. 